\title{
РИСКИ И ПРИЧИНЫ РАЗВИТИЯ АВАРИЙНЫХ СИТУАЦИЙ НА МАГИСТРАЛЬНЫХ ТРУБОПРОВОДАХ
}

\section{Даниил Юрьевич Еськов}

Сибирский государственный университет геосистем и технологий, 630108, Россия, г. Новосибирск, ул. Плахотного, 10, обучающийся, тел. (952)948-67-09, e-mail: yeskovdaniil@gmail.com

\section{Мария Михайловна Шляхова}

Сибирский государственный университет геосистем и технологий, 630108, Россия, г. Новосибирск, ул. Плахотного, 10, кандидат технических наук, доцент кафедры фотограмметрии и дистанционного зондирования, тел. (960)779-62-25, e-mail: plazma_space@mail.ru

В статье рассмотрены проблемы современных систем магистральных трубопроводов. Дано описание линейной части нефтепроводов. Приведены основные причины возникновения аварийных ситуаций. Описаны сценарии развития происшествий и их последствия. Приведены статистические данные аварийных ситуаций с летальным исходом. Представлены факторы, влияющие на частоту возникновения инцидентов аварий. Предложены рекомендации по минимизации вреда при возникновении аварийных ситуаций, включающие в себя стандартные мероприятия и мероприятия с применением средств дистанционного зондирования.

Ключевые слова: магистральные нефтепроводы, экологические риски, причины аварий, методы предотвращения аварий, последствия аварий, дистанционное зондирование

\section{RISKS AND CAUSES OF ACCIDENTS ON MAIN PIPELINES}

\section{Daniil Yu. Eskov}

Siberian State University of Geosystems and Technologies, 10, Plahotnogo St., Novosibirsk, 630108, Russia, Student, phone: (952)948-67-09, e-mail: yeskovdaniil@gmail.com

\section{Maria M. Shlyakhova}

Siberian State University of Geosystems and Technologies, 10, Plakhotnogo St., Novosibirsk, 630108, Russia, Ph. D., Associate Professor, Department of Photogrammetry and Remote Sensing, phone: (960)779-62-25, e-mail: plazma_space@mail.ru

The article deals with the problems of modern trunk pipeline systems. The description of the linear part of oil pipelines is given. The main causes of accidents are given. Scenarios for the development of accidents and their consequences are described. Statistical data on fatal accidents are provided. Factors affecting the frequency of accidents are presented. Recommendations for minimizing harm in the event of emergency situations, including standard measures and measures using remote sensing tools, are proposed.

Keywords: main pipelines, environmental risks, causes of accidents, methods of accident prevention, consequences of accidents, remote sensing 


\section{Введение}

Система магистральных нефтепроводов один из самых экономически эффективных способов доставки нефтепродуктов из мест добычи до мест переработки или экспорта. Она представляет собой комплекс сложных инженерных конструкций, которые используются по всей России в разных климатических условиях. В состав магистральных нефтепроводов входят: линейные сооружения, головные, промежуточные перекачивающие насосные станции, наливные насосные станции, резервуарные парки. В зависимости от ландшафта и климатических условий трубы могут прокладываться над землей (водой) и под землей (водой). Их диаметр обычно составляет от 100 до 1400 мм. Для движения нефти необходимо обеспечить перепад давления, поэтому каждые 70-150 км устанавливаются насосные стации. На случай аварийных ситуаций каждые 10-30 км устанавливаются специальные задвижки. Они используются для временного перекрытия движения сырья или готового продукта. К преимуществам данного вида транспортировки можно отнести: низкую себестоимость, наименьшие потери продуктов, наибольшую автоматизацию, бесперебойную и своевременную доставку продуктов к местам сбыта [1].

\section{Методы и материаль}

За многие годы существования магистральных нефтепроводов человечество достигло значительных успехов в области их проектирования, строительства и эксплуатации, несмотря на это вероятность возникновения аварийных ситуаций все еще присутствует. В результате происходят пожары, загрязнение окружающей среды, разрушения сооружений и гибель людей.

К возможным причинам возникновения аварийных ситуаций на линейной части магистральных нефтепроводов, которые приводят к разгерметизации и выбросам нефтепродуктов относят:

- ошибки при строительстве, включающие в себя повреждения труб (вмятины, царапины) и некачественно выполненные монтажные стыки;

- повреждения, нанесенные в процессе капитального ремонта. К ним относятся поломки манометрических приборов, вантузов, запорной арматуры, сквозные пробоины трубопроводов;

- дефекты в металле труб, запорной арматуре, соединительных деталях трубопровода, некачественная заводская сварка;

- внутренняя и внешняя коррозия. Первая возникает вследствие перекачки обводненной нефти и нефти, содержащей агрессивные компоненты. Вторая возникает из-за некачественного нанесения изоляции при строительстве или естественного строения изоляционного покрытия;

- ошибки при эксплуатации и прочие причины.

Помимо разгерметизации, возможны прорывы трубопроводов. Это случается из-за ошибок строительного и ремонтного персонала и при резком исчезновении напряжения в сети электроснабжения. 
По данным, представленным в отчете Ростехнадзора, за 2019 год произошло 7 несчастных случаев со смертельным исходом (за 2018 год случаев смертельного травматизма не зарегистрировано) (рис. 1).

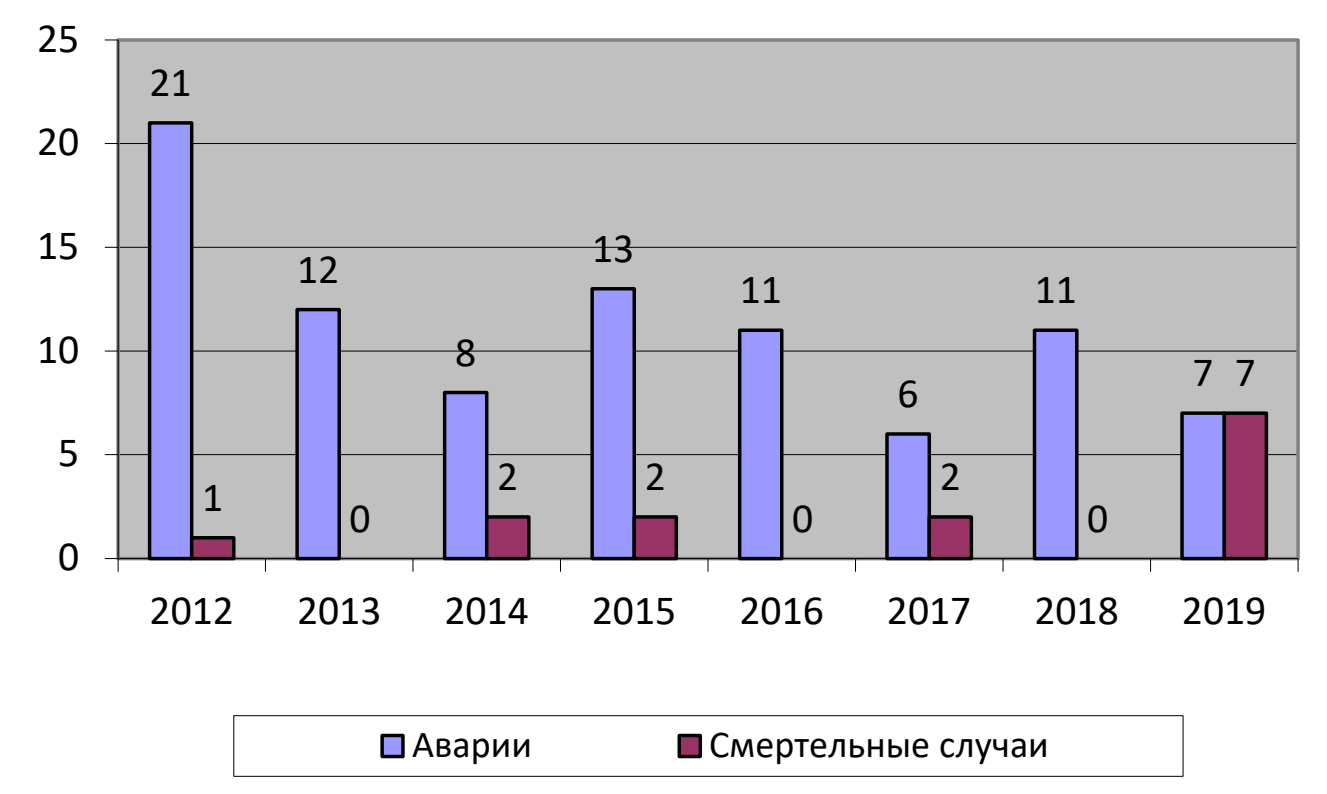

Рис. 1. Динамика показателей аварийности и травматизма на объектах магистрального трубопроводного транспорта

В результате анализа было установлено, что большинство (80\%) аварий в 2019 году произошли из-за неисправностей или физического износа оборудования.

В результате исследования выяснилось, что основными причинами возникновения аварийных ситуаций являлись разгерметизация и разрушение технических устройств (трубопроводов). Это следствие нарушения требований при эксплуатации и техническом обслуживании, а также при осуществлении земляных работ в границах охранной зоны магистральных трубопроводов [2].

Часто причиной аварий становится механическое воздействие на линейную часть нефтепровода. В результате расследования Федеральной службы по экологическому, технологическому и атомному надзору удалось выделить факторы, влияющие на интенсивность возникновения аварийных ситуаций. К ним относят:

- брак в строительстве или в изготовлении трубопровода;

- конструкционные недостатки;

- механическое воздействие;

- износ оборудования;

- несанкционированные врезки;

- нарушение порядка проведения опасных работ [3, 4]. 
При возникновении аварийных ситуаций может быть нанесен вред флоре и фауне, сооружениям, персоналу и населению, находящимся вблизи линейной части магистральных нефтепроводов. В результате разрушений конструкций и утечке продукта могут происходить следующие процессы:

- выброс продукта, с постепенным испарением;

- пожары;

- взрывы;

- детонации;

- разлет осколков;

- воздушные и сейсмические волны.

Чаще всего вышеприведенные причины приводят к разгерметизации и распространению нефти по территории. Это наносит вред не только окружающей среде, но и населению. Часто токсичные пары нефти и прочие выбросы приводят к тяжелым заболеваниям и летальным последствиям (рис. 2) [5, 6, 7].

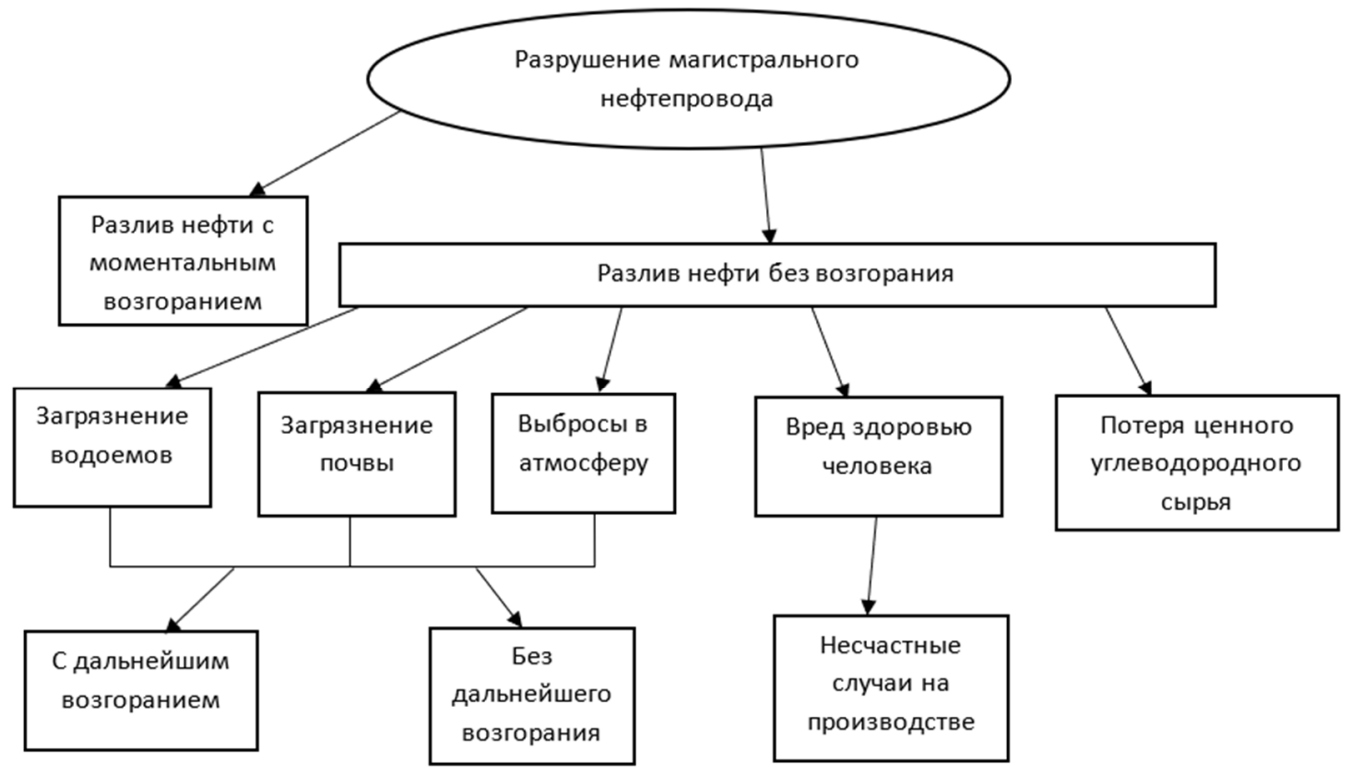

Рис. 2. Последствия возникновения аварийных ситуаций

\section{Результатьи}

Для предупреждения аварийных ситуаций необходимо использовать инновационные методы воздушного и наземного мониторинга. Внедрение беспилотных летательных аппаратов, оснащенных телевизионной аппаратурой и фотокамерами позволит быстро реагировать на утечки сырья и незаконные врезки с целью хищения нефтепродуктов. Беспилотные летательные аппараты, оснащенные радаром (SAR) помогут в предотвращении аварийных ситуаций, возникающих при изменении напряженно-деформированного состояния трубопроводных конструкций $[8,9,10]$. 
Для предотвращения возникновения аварийных ситуаций на магистральных нефтепроводах и снижения их последствий, предприятиям, работающим в данной области, следует выполнять следующие рекомендации:

- следить за качеством построенных объектов;

- обеспечивать бесперебойную работу и надежную эксплуатацию оборудования с помощью новых технологий и материалов;

- осуществлять контроль исполнения правил эксплуатации и своевременного, качественного выполнения аварийно-ремонтных и восстановительных работ;

- своевременно выявлять дефекты оборудования и осуществлять их ремонт или замену;

- выполнять требования техники безопасности и охраны труда, а также регулярно обучать, тестировать и тренировать персонал.

\section{Заключение}

На современном этапе развития невозможно полностью исключить вероятность возникновения аварийных ситуаций при перекачке нефтепродуктов. Несмотря на это, профильным предприятиям следует уделять большее внимание внедрению новых перспективных технологий, таких как дистанционное зондирование. Это окажет большое влияние на минимизацию рисков возникновения аварий, тем самым снизив потери и уменьшив негативное воздействие на окружающую среду.

Работа выполнена в рамках государственного задания Минобрнауки России (тема «Разработка теории и технологических решений контроля состояния защитных сооружений при перекачке нефтепродуктов методами активного дистанционного зондирования», № 0807-2020-0002).

\section{БИБЛИОГРАФИЧЕСКИЙ СПИСОК}

1. Аскаров Р.М., Китаев С.В., Исламов И.М. О технологии выявления участков трубопроводов с изгибными напряжениями при пересечении ими геодинамических зон // Изв. Том. политехнич. ун-та. Инжиниринг георесурсов. -2019. -Т. 330, -№ 5. -С. 18-25.

2. Отчет Федеральной службы по экологическому, технологическому и атомному надзору. URL: http://www.gosnadzor.ru/public/annual_reports/.

3. Гайсина Д.Р., Денисова Я.В. Анализ причин аварийных ситуаций на магистральных трубопроводах // Вестник технологического университета. - 2016. -№14. -Т.19. -С. 129-130.

4. Поникаров С. И., Алексеев В.А., Вилохина П.В., Маннанова А.Ф. Анализ причин возникновения аварий на магистральных нефтепроводах // Вестник технологического университета. - 2014. -№6. -С. 365-368.

5. Чухарева Н.В., Савинский Р.В., Блохина О.Л. Анализ развития аварийных ситуаций при строительстве и эксплуатации трубопроводных систем в условиях Западной Сибири // Горный информационно-аналитический бюллетень. - 2011. - №12. -С. 454-460.

6. Алексеев В.А., Алексеев С.В., Миннегалеев А.Н., Ахметов Р.Р. Моделирование процесса разлива нефти и нефтепродуктов при разгерметизации на подводных переходах магистральных нефтепроводов // Вестник Казанского технологического университета. - 2011. -№8. -С.172-177. 
7. Стадикова М.А., Глебова Е.В., Мударова А.В., Шейнкман Л.Э. Анализ аварийных ситуаций и их последствия на магистральных нефтепроводах // Экология и промышленность России. - 2009. - №8. -С. 22-24.

8. Дедкова В.В., Шляхова М.М. Мониторинг технического состояния магистральных трубопроводов методами дистанционного зондирования // Материалы VII Международной конференции «Региональные проблемы дистанционного зондирования Земли». Красноярск: СФУ. -2020. -С. 192-195.

9. Кугрышева Л.И., Стахов С.А. Факторы обеспечения надежности и безопасности трубопроводов // Сборник научных трудов СевКавГТУ. - 2008. - №4. -С. 134-137.

10. Вицин Д.Ю., Алексеев В.А. Моделирование аварийного истечения нефтепродуктов на проницаемой поверхности // Вестник Казанского технологического университета. - 2014. №4. -T. 17. -С. 216.

(с) Д. Ю. Еськов, М. М. Шляхова, 2021 